\title{
A NEW METHOD TO PREDICT TEMPERATURE DISTRIBUTION ON A TUBE AT CONSTANT HEAT FLUX
}

\author{
Ali Habeeb Askar \\ PhD student, University of Miskolc, Institute of Physics and Electric Engineering \\ University of Technology - Iraq \\ 3515 Miskolc, Miskolc-Egyetemváros,e-mail:20156@uotechnology.edu.iq \\ Hazim Albedran \\ PhD student, University of Miskolc, Institute of Energy Engineering and Chemical Machinery \\ University of Kufa, Najaf, Iraq \\ 3515 Miskolc, Miskolc-Egyetemváros, e-mail:vegyhnr@uni-miskolc.hu \\ Endre Kovács \\ associate professor, University of Miskolc, Institute of Physics and Electric Engineering \\ 3515 Miskolc, Miskolc-Egyetemváros, e-mail: fizendre@uni-miskolc.hu \\ Károly Jármai \\ professor, University of Miskolc, Institute of Energy Engineering and Chemical Machinery \\ 3515 Miskolc, Miskolc-Egyetemváros, e-mail: altjar@uni-miskolc.hu
}

\begin{abstract}
Surface temperature distribution on a tube is one of the main factors affecting the calculation of the heat transfer coefficient calculation. When an electric heater heats the tube, a magnetic flux is generated that affects the thermocouples readings; therefore, an efficient fitting technique is needed to represent these readings. This work proposes an interpolated spline method to mathematically represent experimental data of a thermal distribution on a tube with heat flux. Linear regression was compared with a double linear interpolation process with an optimization algorithm and cubic spline curve method on the proposed problem. The results show that the interpolated experimental data can highly improve the regression of the spline curve. Consequently, an interpolated spline curve gives better surface temperature distribution and better estimation for the average temperature. The interpolated points on spline segments are chosen by an optimization algorithm, which is particle swarm optimization, in a way that provides more minor errors.
\end{abstract}

Keywords: Temperature distribution, Heat transfer, Interpolated spline; Optimization; Curve fitting.

\section{Introduction}

A heat exchanger is a device used to heat transfer between two or more fluids for various applications, including power plants, nuclear reactors, refrigeration and air condition systems, automotive industries, heat recovery systems, chemical processing and food industries. In order to calculate the heat transfer knowledge of the prevailing temperature field is the first requirement. Most calculating the temperature distribution methods within a tube wall are given in the literature by constant wall temperature (Askar et al., 2020) or constant heat flux (Karamallah et al., 2016). The heat transfer equipment industry is a vast and expensive part of the world economy due to the cost and size of the heat transfer equipment. A large part of this cost in the industry is due to rising fuel prices. As a result, methods to enhance the heat 
transfer process are of great interest, because even small reductions in fuel costs could make the difference between a successful and failing power industry (Rohsenow et al., 1998). Industrial waste heat is energy that exists in industrial processes that is not put to any application use and is lost, wasted and dumped into the environment (Siddique et al., 2010). Waste heat recovery can be performed through various waste heat recovery techniques to provide valuable energy sources, reduce energy consumption in general and preserve the environment by reducing emissions to the atmosphere (Mardiana-Idayu and Riffat, 2012). Temperature profiling in both fluid and pipe walls have been explained theoretically (Emetere, 2014). The research was conducted on the operation and performance of commonly used technologies such as recuperates and generators, including kiln regenerators, rotary regenerators or heat wheels, passive air heaters (O'Connor et al., 2016), regenerative incinerators and recuperates, plate heat exchangers, economizers and units such as waste heat and revolving coil (RAC) boilers (Jouhara et al., 2018). The authors provided a hitherto new approach of a heat transfer correlation based on heat flux to mass flux ratio for predicting the wall temperature of supercritical water flowing in a bare vertical tube.

One of the most important issues in heat exchanger functionality and design is representing the thermal distribution across the walls of pipes. Curve fitting is employed to develop a relationship between temperature and wall thickness. There are several works that used optimization techniques (Ghafil and Jármai, 2020a) to find the best curve that fits all the experimental data. Optimization is the problem of maximizing or minimizing quantities (Ghafil et al., 2021) that are part of engineering or mathematical problems (Ghafil and Jármai, 2020b). The type of metaheuristic algorithm that should be used for curve fitting is depending on the fitting problem itself. Some simple problems may need a single algorithm, and other complicated fitting problems can only be solved by multiple metaheuristics working in parallel to have a good degree of fitting (Alsamia et al, 2021). This paper, we have found a new regression method for optimal mathematical representation of experimental data called interpolated spline curve. The proposed method is based on knote spline and particle swarm optimization (Ghafil and Jármai, 2018), and the method was compared with spline. The results of the comparison reveal that the interpolated spline method has outperformed the fitting results of spline curves. Interpolated spline curve method is highly depends on the number of control points and position of that points on the curve.

\section{Methodology}

\subsection{The Test Section}

The rig is a copper tube of $1.58 \mathrm{~cm}$ outer diameter and $1.4 \mathrm{~cm}$ inner diameter, with $150 \mathrm{~cm}$ length. The tube outer surface is electrically heated by a coil made from Nichrome material with power connected to an AC power supply to generate heat flux. It is $(16.7 \mathrm{~m})$ long and $(1.25 \mathrm{~mm})$ diameter of wire with $(1.36 \Omega / \mathrm{m})$ resistance (AWG is 16$)$. An electric insulator of fiberglass is wrapped around the tube. Drilled ceramic bead elements are inserted around the wire heater to insulate the electrical heater, and then the wire heater is wrapped around the pipe. An aluminum foil and sectional pipe insulation of glass wool type with $1.9 \mathrm{~cm}$ internal diameter and $6.35 \mathrm{~cm}$ outer diameter thermal insulation operating in temperature up to $\left(230^{\circ} \mathrm{C}\right)$ nominal density is $\left(64 \mathrm{~kg} / \mathrm{m}^{3}\right)$ used to insulate the testing tube. Eight thermocouples (type-K) are used to measure the temperatures in different locations in the test rig. Six thermocouples are used to measure the surface temperatures along the outer surface of the tube. The thermocouples are located along the test section with a space distance of $(22 \mathrm{~cm})$ between them. Two thermocouples are immersed in the flow to measure the inlet and outlet temperatures of the fluid in the test section. 


\subsection{Theory}

To calculate the heat transfer coefficient inside the tubes, we need the temperature of the fluid entering and leaving the tube to know the properties and behaviour of the fluid; also the temperature distribution during the flow (surface temperature on the tube) is essential because it is difficult to measure it in practice, by fixed a thermocouple along the length of the pipe. This method has many problems, for example, the accuracy of measurement, methods of installation, and the number of thermocouples used.

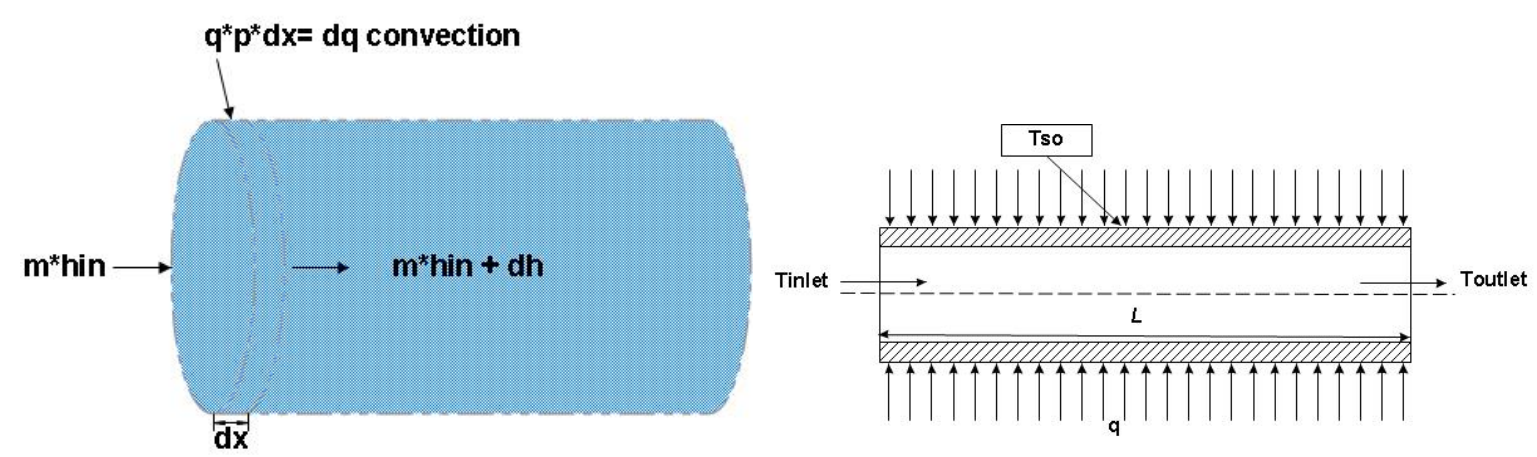

Figure 1. Show the energy balance and section for the tube.

Table 1. shows the experimental data for the surface temperature along the tube, divided into equal spaces, measured by the thermocouples type $(\mathrm{K})$ with different flow rates for each experiment.

Table. 1. The experimental data of temperature.

\begin{tabular}{|l|l|l|l|l|l|l|l|l|l|}
\hline $\mathrm{X}, \mathrm{m}$ & \multicolumn{9}{|l|}{ Temperature, ${ }^{\circ} \mathrm{C}$} \\
\hline 0 & 45.1 & 45.6 & 45.5 & 45.5 & 45.4 & 45.5 & 45.3 & 45.1 & 45.2 \\
\hline 0.22 & 62.1 & 62.3 & 60.1 & 59.5 & 58.9 & 56.3 & 56.2 & 56.1 & 55.2 \\
\hline 0.44 & 65.3 & 63.6 & 61.4 & 61.2 & 61.2 & 57.8 & 57.1 & 56.5 & 55.7 \\
\hline 0.66 & 64.4 & 62.9 & 60.2 & 60.1 & 60 & 57.4 & 56.5 & 55.7 & 55.5 \\
\hline 0.88 & 64.7 & 63.4 & 60.7 & 59.9 & 59.7 & 57.9 & 56.8 & 55.9 & 55.8 \\
\hline 1.1 & 65.6 & 65.1 & 62.1 & 61 & 60.2 & 58.8 & 57 & 56.6 & 56.4 \\
\hline 1.32 & 66.8 & 66.9 & 63.4 & 62.3 & 61.5 & 59.7 & 57.7 & 57.3 & 56.7 \\
\hline 1.54 & 55.3 & 53.5 & 52.2 & 51.3 & 50.6 & 50.2 & 49.9 & 49.6 & 49.4 \\
\hline flow rate, L/min & 1 & 1.5 & 2 & 2.5 & 3 & 3.5 & 4 & 4.5 & 5 \\
\hline
\end{tabular}

By applying the steady-state energy balance on a slice of the tube (control volume) as shown in Figure 1. (Bergman et al., 2006), the rate of heat that gained from the fluid is:

$$
Q_{i n}-\dot{W}_{\text {in }}+\dot{m} H_{\text {in }}-\dot{m} H_{e}=0 .
$$

Since, $\dot{W}_{\text {in }}=0,\left(\mathrm{H}_{e}=\mathrm{H}_{\text {in }}+d \mathrm{H}\right)$ and $Q$ in $=\dot{q}_{\text {in }} d A_{\text {sin }}=\dot{q} p d x$, then;

$$
\dot{q} d A_{\text {sin }}+\dot{m} H_{\text {in }}-\dot{m} H_{\text {in }}-\dot{m} d H=0,
$$

where $d H=C p * d T b(x)$, As, in = circumference $\times$ length $=p d x$, then;

$$
\dot{q}_{\text {in }} p d x=\dot{m} \operatorname{Cp} d T b(x) \text {, }
$$


where $Q$ : heat transfer, $\dot{W}$ : work done, $\dot{m}$ : mass flow rate, $H$ : enthalpy, A: area, $C p$ : specific heat, $T$ : temperature, $L$ : length, $x$ : distance, in :inlet, $e$ : exit, $s$ : surface, $b$ : bulk.

According to Newton's law of cooling:

$$
Q_{\text {in }}=h(x) A s[T s(x)-T b(x)] .
$$

The heat flux will be:

$$
\dot{q}_{\text {in }}=h(x)[T s(x)-T b(x)]
$$

Then, the local heat transfer coefficient is:

$$
\begin{gathered}
h(x)=\dot{q}_{\text {in }}\left[T_{s}(x)-T_{b}(x)\right], \\
\bar{h}=\frac{1}{L} \int_{0}^{L} h(x) d x,
\end{gathered}
$$

where: $\dot{q}$ : heat flux per meter square, $h$ : heat transfer coefficient, $\bar{h}$ : average heat transfer coefficient. Furthermore, by spline, we estimate the average surface temperature and calculate the heat transfer coefficient directly:

$$
\dot{q}_{\text {in }}=\bar{h}\left[T_{K}-T b\right],
$$

where $T_{K}$ : is the average surface temperature evaluated by interpolated spline method.

Flow inside passages is the most common application of Fluid Mechanics and heat transfer. The tests were carried out under developing the turbulent flow of Reynolds number range (3000-10000) with uniform heat flux. The surface temperature varied along the pipe length and increased as the axial distance increased due to the uniform heat flux effect on the surface. The highest surface temperature appeared at the lowest value of Reynold number. Also, the surface temperature decreased, as the Reynold number increased due to the increasing of water velocity, the value in the circular tube is typically above 2300. This is called (Turbulent Flow) in this case the velocity and temperature continuously fluctuate with time.

\section{Particle Swarm Optimization}

Particle swarm optimization (PSO) is one of well-known metaheuristics that is used to solve optimization problems. This algorithm is developed to simulate the behaviour of flocks of animals in nature while they are moving in synchronous groups. This algorithm is simple and easy to implement by any programming language. Figure 2. is the scheme that represents a single particle in a flok of points in space. Each particle is assumed to have position and velocity, and they are denoted by

$$
\begin{aligned}
& x_{k}(t) \in X, \\
& v_{k}(t) \in x,
\end{aligned}
$$

where $k$ is the index of the particle in the swarm and $x$ is the Search space while $t$ is a discrete-time step and it shows the iteration number of the algorithm. The $x_{k}(t)$ is the current location of the particle and it has to move to the new position $x_{k}(t+1)$. Each particle has its own experience and its own memory about the best position where it was, and it is called the personal best of the $\mathrm{k}^{\text {th }}$ particle and denoted by 
$p_{k}(t)$. The particle moves from its position with a velocity in the direction of $v_{k}(t)$. The particles are working together, they are communicating, and interacting with each other and share their personal experience so they can learn and know what is the best experience in the party, which is called global best and denoted by $G(t)$. The following quantities can be extracted from Figure 2 .

The value of the vector connecting the current location and the personal best is:

$$
p_{x}=p_{k}(t)-x_{k}(t)
$$

Also, the value of the vector connecting the current location to the global best is:

$$
g_{x}=G(t)-x_{k}(t) .
$$

The particle has to move the new position; this movement can be expressed as:

$$
\begin{gathered}
x_{k}(t+1)=x_{k}(t)+v_{k}(t+1), \\
v_{k}(t+1)=w v_{k}(t)+C_{1}\left(p_{k}(t)-x_{k}(t)\right)+C_{2}\left(G(t)-x_{k}(t)\right) .
\end{gathered}
$$

In equation (11), the vector $v_{k}(t+1)$ is the summation of the three sub-movements $m_{1}, m_{2}$ and $m_{3}$ where they are the movement of the particle along the vectors $v_{k}(t), p_{x}$ and $g_{x}$ respectively, so we can write:

$$
v_{k}(t+1)=m_{1}+m_{2}+m_{3}
$$

where

$$
\begin{gathered}
m_{1}=w v_{k}(t), \\
m_{2}=C_{1} p_{x}=C_{1}\left(p_{k}(t)-x_{k}(t)\right), \\
m_{3}=C_{2} g_{x}=C_{2}\left(G(t)-x_{k}(t)\right) .
\end{gathered}
$$

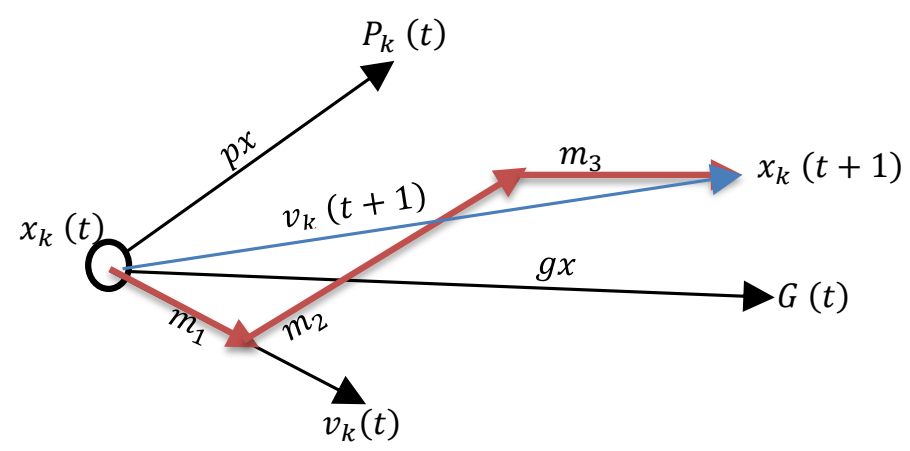

Figure 2. Schematic diagram representing the mathematical model of PSO.

Equations (10) and (11) completely describe the mathematical model of PSO. However, these equations are simple mathematical models behind the standard PSO, and some situations are necessary to complete the equations. The standard PSO is as follows 


$$
\begin{gathered}
x_{k j}(t+1)=x_{k j}(t)+v_{k j}(t+1), \\
v_{k j}(t+1)=w v_{k j}(t)+r_{1} C_{1}\left(p_{k j}(t)-x_{k j}(t)\right)+r_{2} C_{2}\left(G_{j}(t)-x_{k j}(t)\right),
\end{gathered}
$$

where

$v_{k j}(t+1)$ : denote the velocity of particle $k$ in time step $(t+1)$ of the $j^{t h}$ component for this velocity,

$r_{1}, r_{2}:$ a random number uniformly distributed in the range $(0: 1)$,

$C_{1}, C_{2}$ : acceleration coefficient,

$w v_{k j}(t)$ : inertia term,

$w:$ inertia coefficient,

$r_{1} C_{1}\left(p_{k j}(t)-x_{k j}(t)\right):$ cognitive component,

$r_{2} C_{2}\left(G_{j}(t)-x_{k j}(t)\right)$ : social component.

The parameters of the PSO in this study; population size is 50, No. of iteration is 500, and No. of independent runs is 30 , each run starts with random solution. $C_{1}$ and $C_{2}$ are equal to one and inertia term is 0.95 . Number of variables are eight position vectors and each vector consists of two variables $x, y$ in total there are 16 independent variables, these variables represent the interpolated points. For each flow rate, there are nine experimental data shown in Table 1. and these data used as control points. There should be eight In between points among the control points that are affecting the final shape of the fitting curve and these in between points are the interpolated points that is optimized by the PSO algorithm.

\section{Interpolated spline curve}

In this section, the efficiency of the knot spline curve is improved by considering interpolated points which are represented in the cross symbol in Figure 4.a. The position of the interpolated points is highly affecting the final shape of the spline, consequently, the efficiency of the fitting process. The domain between adjacent segments is continuous; therefore, an optimization algorithm is proposed to create and optimize the interpolated points. Any optimization algorithm can be used for this purpose since all of them share similar principles. Particle Swarm Optimization (PSO) (Ghafil and Jármai, 2018) is used for the optimization problem where it is responsible for the optimal positions of the interpolated points on each successive control point. Figure 4.b. reveals the interpolated spline curve with experimental data where it is clear; the developed curve greatly matches the experiments.

The objective function is described by the following

$$
f=\sum_{i=1}^{n}\left\|y_{p i}-y_{a i}\right\|
$$

where $f$ is the objective function that should be minimized, $y_{p}$ is the y-coordinates on experimental data, $y_{a}$ is the y-coordinates on the fitting curve, and $i$ is the index of the experimental data in the set of $n$ experiments. Figure 3. shows the representation of the objective function which is described by equation (18). Also, $f$ is a real positive value represents the objective function value (cost function) and that real positive number is the summation of the absolute distances between each $y$-axis on fitting curve $\left(y_{p i}\right)$ and y-axis of the real data or the experiment $\left(y_{a i}\right)$. 


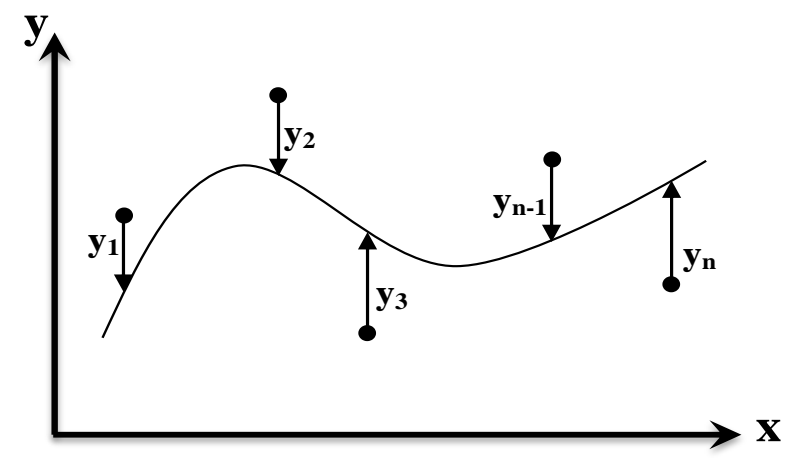

Figure 3. Representation of the objective function.

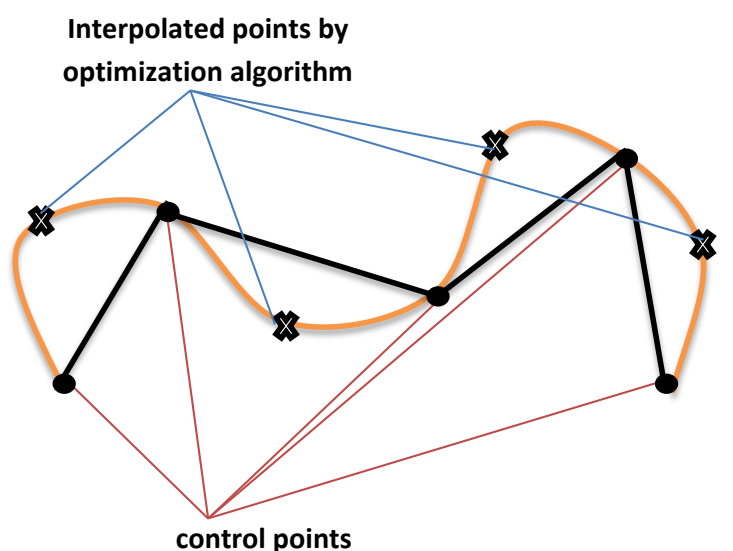

a.

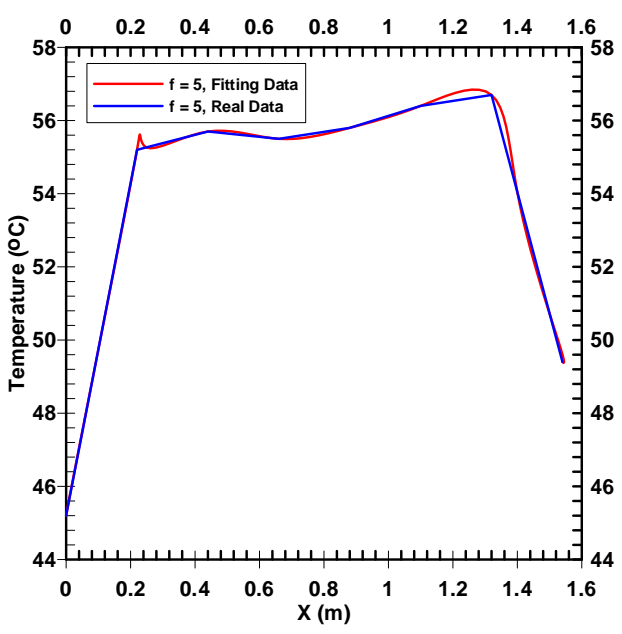

b.

Figure. 4. a. Interpolated spline formulation, $\boldsymbol{b}$. Interpolated spline curve fitting real data.

The cubic spline in Figure 4. represents the experimental data on the continuous domain $[0,1.6]$ smoothly and perfectly except for a subdomain [0.23, 0.28]. This is an acceptable error on the method that can be overcome by increasing the number of interpolated points developed by the optimization algorithm.

For the other hand, we can consider a single linear piecewise function for the eight experimental data in Table 1., then we have seven segments or say seven domains for the piecewise function. This work is trying to replace the linear piecewise function with its 7 domain with a single continuous nonlinear fitting equation with a single domain $[0,1.6]$.

Table 2. shows the statistical results between using spline method and interpolated spline method where it is clear the interpolatd spline method has better performance.

\section{Results and discussion}

The results for forced convection turbulent flow conditions and uniform heat flux are exposed, and discuss the surface temperature from experimental results is analysed to find a correlation for temperature 
distribution and indicate the reasons behind such results. Experimental and theoretical results are presented and discussed. The surface temperature varied along the pipe length and increased as the axial distance increased due to the uniform heat flux effect on the surface, and the surface temperature decreased with the increased flow rate of water. As you see in Figure 5. the surface temperature distribution along the test section for different Reynold numbers for the distilled water. The highest surface temperature appeared at the lowest value of the Reynold number. The validation of the experimental result validity in convective heat transfer calculations as well as to provide a reference for comparison. The Gnielinski equation calculates the predicted heat transfer coefficient. The experimental behaviour was conformable to the predicted values, and we get heat transfer improvement from the spline curve.

Table. 2. Spline method vs interpolated spline methods using PSO.

\begin{tabular}{|l|l|l|l|l|}
\hline \multicolumn{2}{|l|}{ Experimental data } & Method & $\mathrm{y}_{f}$-axis & error\% \\
\hline $\mathrm{x}$-axis & $\mathrm{y}$-axis & & & \\
\hline \multirow{2}{*}{0.1} & 49.74 & Interpolated spline & 49.61 & $0.26 \%$ \\
\cline { 3 - 5 } & & Spline & 55.89 & $12.3 \%$ \\
\hline \multirow{2}{*}{0.3} & \multirow{2}{*}{0.365} & Interpolated spline & 55.47 & $0.19 \%$ \\
\cline { 3 - 5 } & & Spline & 55.9 & $0.96 \%$ \\
\hline \multirow{2}{*}{0.5} & \multirow{2}{*}{1.6 .645} & Interpolated spline & 55.73 & $0.15 \%$ \\
\cline { 3 - 5 } & & Spline & 55.558 & $0.15 \%$ \\
\hline \multirow{2}{*}{1.4} & \multirow{2}{*}{56.53} & Interpolated spline & 56.8 & $0.47 \%$ \\
\cline { 3 - 5 } & & Spline & 56.9 & $0.65 \%$ \\
\hline & \multirow{2}{*}{} & Interpolated spline & 54.1 & $0.07 \%$ \\
\cline { 3 - 5 } & Spline & 55.401 & $2.4 \%$ \\
\hline
\end{tabular}

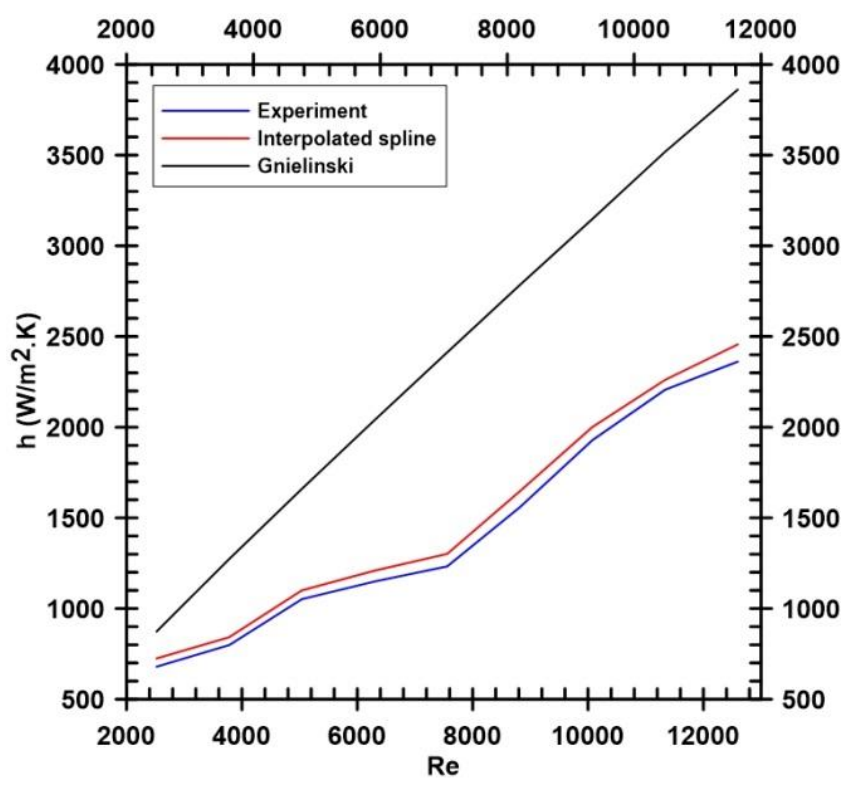

Figure 5. Experimental and theoretical (Gnielinski equation (Gnielinski, 1975)) of Reynold number vs heat transfer coefficient. 


\section{Conclusion}

This paper discusses the temperature distribution in the tube and estimates the heat transfer coefficient. Then, an interpolated cubic spline curve was developed to fit experimental data and represent them in the best possible equation. The interpolated spline was compared with the linear regression method and pure knot spline on the same experiments. The proposed interpolated spline overcomes linear regression and pure knot spline in fitting the data set. The interpolated spline was used to calculate the average surface temperature; after that, we used it to calculate convection heat transfer. Used this method is essential and have many applications; for example, in a flat plate collector, we need surface temperature and any temperature for the surface we have used; thus we can use randomly thermocouples on the surface and then find by spline the temperature of the surface.

\section{Acknowledgements}

The research was supported by the Hungarian National Research, Development and Innovation Office under the project number K 134358, and by the NTP-SZKOLL-20-0022 identifier "Focus'21-Focus on community by developing digital competencies" project, supported by the Ministry of Human Resources and Human Resources Support Manager.".

\section{References}

[1] Askar, A. H., Kadham, S. A., Mshehid, S. H. (2020). The surfactants effect on the heat transfer enhancement and stability of nanofluid at constant wall temperature. Heliyon, 6(7), e04419. https://doi.org/10.1016/j.heliyon.2020.e04419

[2] Karamallah, A. A., Habeeb, L. J., Asker, A. H. (2016). The effect of magnetic field with nanofluid on heat transfer in a horizontal pipe. Al-Khwarizmi Eng. J., 12(3), 99-109.

[3] Rohsenow, W. M., Hartnett, J. P., Cho, Y. I. (1998). Handbook of heat transfer, vol. 3. McGrawHill, New York.

[4] Siddique, M., Khaled, A.-R., Abdulhafiz, N. I., Boukhary, A. Y. (2010). Recent advances in heat transfer enhancements: a review report. Int. J. Chem. Eng., 2010. https://doi.org/10.1155/2010/106461

[5] Mardiana-Idayu A., Riffat, S. B. (2012). Review on heat recovery technologies for building applications. Renew. Sustain. Energy Rev., 16(2), 1241-1255.

https://doi.org/10.1016/j.rser.2011.09.026

[6] Emetere, M. E. (2014). A model for analyzing temperature profiles in pipe walls and fluids using mathematical experimentation. Adv. Mech. Eng., 2014(1). https://doi.org/10.1155/2014/490302

[7] O'Connor, D., Calautit, J. K., Hughes, B. R. (2016). A novel design of a desiccant rotary wheel for passive ventilation applications. Appl. Energy, 179, 99-109.

https://doi.org/10.1016/j.apenergy.2016.06.029

[8] Jouhara, H., Khordehgah, N., Almahmoud, S., Delpech, B., Chauhan, A., Tassou, S. A. (2018). Waste heat recovery technologies and applications. Therm. Sci. Eng. Prog., 6(January), 268-289. https://doi.org/10.1016/j.tsep.2018.04.017

[9] Ghafil, H. N., Jármai, K. (2020a). Dynamic differential annealed optimization: New metaheuristic optimization algorithm for engineering applications. Appl. Soft Comput., 106392. https://doi.org/10.1016/j.asoc.2020.106392

[10] Ghafil, H. N., Alsamia, S., Jármai, K. (2021). Fertilization optimization algorithm on CEC2015 and large scale problems. Pollack Period., 2021. 
[11] Ghafil, H. N., Jármai, K. (2020b). Optimization for Robot Modelling with MATLAB. Springer Nature. https://doi.org/10.1007/978-3-030-40410-9

[12] Alsamia, S., Ibrahim, D. S., Ghafil, H. N. (2021). Optimization of drilling performance using various metaheuristics. Pollack Period., 2021. https://doi.org/10.1556/606.2021.00307

[13] Ghafil, H., Jármai, K.: Comparative study of particle swarm optimization and artificial bee colony algorithms, 2018 Multiscience XXXII. MicroCAD International Multidisciplinary Scientific Conference, Miskolc-Egyetemváros, Hungary, pp. 1-6. https://doi.org/10.26649/musci.2018.030

[14] Bergman, T. L., Incropera, F. P., Lavine, A. S., Dewitt, D. P. (2006). Introduction to heat transfer Fifth. John Wiley \& Sons Hoboken, United States.

[15] Gnielinski, V. (1975). New equations for heat and mass transfer in the turbulent flow in pipes and channels. NASA STI/recon Tech. Rep. A, 41(1), 8-16. 